Position-Paper (accessed 14 July 2014).

6. Bose D, Meric-Bernstam F, Hofstetter W et al. Vascular endothelial growth factor targeted therapy in the perioperative setting: implications for patient care. Lancet Oncol 2010; 11: 373-382.

7. D Mellor J, Cassumbhoy M, Jefford M. Clinical guidance on the perioperative use of targeted agents in solid tumor oncology. Asia-Pac J Clin Oncol 2011; 7: 106-113.

8. Sharma K, Marcus J R. Bevacizumab and wound healing complications: mechanisms of action, clinical evidence and management recommendations for the plastic surgeon. Ann Plast Surg 2013; 71: 434-440.

DOI: $10.1038 / s j . b d j .2014 .811$

\section{DENTAL PATIENTS}

\section{A terrible disservice}

Sir, time was when all health professionals had one thing in common - patients. Back in 2006 one NHS Trust ordered staff not to refer to people receiving medical care as patients but as clients. Was this the beginning of the change highlighted in your timely editorial (Patients are a virtue; 217: 53)?

Now even our regulators are referring to those who use our services as customers, not only demonstrating a misunderstanding of our roles but also devaluing both practitioners and those that we care for. Patients are not simply clients or users of health services. Patients are those receiving care, who are given time, are listened to and treated with sympathy, understanding and expertise. There is something special about the term 'patient', and although to give a precise definition is difficult, it is well understood by those who deliver the care.

We, like all health professionals, are not simply service providers and those who describe us as such do us and the patients that we care for a terrible disservice.

\section{G. Feaver, New Malden} DOI: 10.1038/sj.bdj.2014.813

\section{Mafia regulation}

Sir, thank you for your editorial of 25 July 2014 regarding the rebranding of 'patients' as 'customers' (217: 53).

This is part of the inappropriate application of the world of commerce to healthcare, also evident in the NHS Friends and Family Test which will soon be mandatory in all NHS dental practices.

NHS healthcare in particular - where people are being treated not because they want to be, but because they are suffering from an affliction that they did not desire - is not the place to be judging outcomes by the standards of the supermarket. People who suffer and want that suffering to be relieved are not customers, clients, or consumers. They are patients!

I note with some regret that registrants are now 'customers' of the GDC (if you want to make a complaint about them on the website at least!). The $O E D$ defines a customer as 'A person who buys goods or services from a shop or business' which definition might just fit our patients, but certainly does not fit registrants of the GDC.

Indeed the GDC is more like the Mafia - providing no goods nor services to its 'customers', but demanding increasing amounts money just to allow them to work in a job for which they are trained. And woe betide you if you don't pay up!

Like many others I welcome the recent BDA stance against the increasingly out of touch GDC and the unprecedented increase proposed for the ARF. Our Association should also make a stand against the inappropriate application of commercial terms and practices to healthcare.

C. J. Rushforth, Bath DOI: 10.1038/sj.bdj.2014.814

\section{Changing nomenclature}

Sir, your editorial Patients are a virtue (BDJ 2014; 217: 53) astutely assesses the changing nomenclature, and more importantly, the changing attitude of the treatment philosophy of the dental profession. Here in North America, patients are described as 'clients', and the conduct of a dental practice is a business. In fact, dental practitioners are business persons who happen to possess a dental licence.
Their treatment protocol is based upon the ability of their 'clients', or more often, the client's dental insurance company, to pay for treatment required. Advertising of dental services is rife, and has immeasurably lowered the prestige of the profession in public opinion. The professed altruism of patient healthcare is unfortunately too often a secondary consideration.

G. H. Sperber, Edmonton, Canada DOI: 10.1038/sj.bdj.2014.815

\section{Bah humbug}

Sir, a person (no ageism, racism or sexism implied) is involved in a road traffic accident and suffers severe lower body injuries. The paramedics who scrape them off the tarmac and do immediate lifesaving procedures are regulated by the Health \&t Care Professions Council. The HCPC's role: 'Regulating health, psychological and social work professionals.' The doctors who treat them in hospital are regulated by the General Medical Council. The GMC's mission statement: 'Regulating doctors, ensuring good medical practice.'

These good souls are helped and the patient's well-being aided by nurses who are responsible to the Nursing \& Midwifery Council. The NMC's role: 'To safeguard the public by ensuring nurses and midwives consistently deliver high quality healthcare.' There is also input from more members of the HCPC group eg radiographers, physios.

Drugs, etc are provided by the pharmacists who are regulated by the General Pharmaceutical Council. The role of the GPC: 'Upholding standards and public trust in pharmacy.'

After a year they leave the hospital and eventually decide they need a dental examination and maybe a scale and polish. Now they need protecting? In the words of Ebenezer Scrooge: 'Bah, humbug.'

A. Caen

By email DOI: 10.1038/sj.bdj.2014.816 